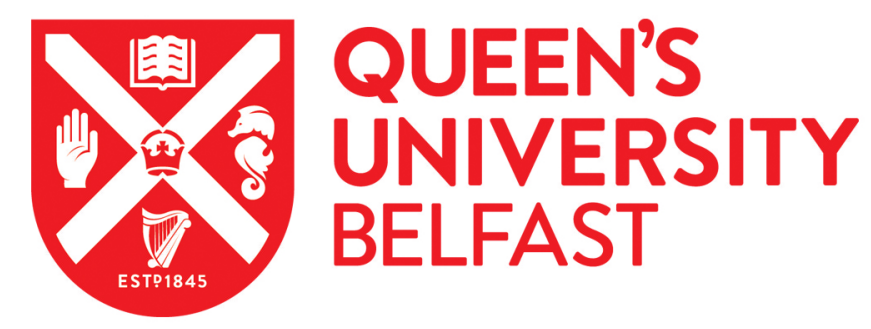

\title{
An Evaluation of Mental Health Service Provision in Northern Ireland
}

Montgomery, L., Wilson, G., Houston, S., Davidson, G., \& Harper, C. (2019). An Evaluation of Mental Health Service Provision in Northern Ireland. Health and Social Care in the Community, 27(1), 105-114. https://doi.org/10.1111/hsc.12627

Published in:

Health and Social Care in the Community

Document Version:

Peer reviewed version

Queen's University Belfast - Research Portal:

Link to publication record in Queen's University Belfast Research Portal

Publisher rights

(c) 2018 John Wiley \& Sons Ltd. This work is made available online in accordance with the publisher's policies. Please refer to any applicable terms of use of the publisher.

\section{General rights}

Copyright for the publications made accessible via the Queen's University Belfast Research Portal is retained by the author(s) and / or other copyright owners and it is a condition of accessing these publications that users recognise and abide by the legal requirements associated with these rights.

Take down policy

The Research Portal is Queen's institutional repository that provides access to Queen's research output. Every effort has been made to ensure that content in the Research Portal does not infringe any person's rights, or applicable UK laws. If you discover content in the Research Portal that you believe breaches copyright or violates any law, please contact openaccess@qub.ac.uk. 
Montgomery, L, Wilson. G., Houston, S., Davidson, G., Harper, C ( 2018) An Evaluation of Mental Health Service Provision in Northern Ireland in

Health \& Social Care in the Community

\begin{abstract}
.
Although Northern Ireland has high levels of mental health problems, there has been a relative lack of systematic research on mental health services that can provide an evidence base for legal, policy and service developments. This article aims to provide a review of the central issues relating to mental health service provision in Northern Ireland, and to gather the perceptions of different stakeholders of these services. The study utilised in-depth qualitative interviews, focus groups and an on-line survey to collect data from respondents throughout the region. This method involved the completion of semi-structured interviews with significant mental health commissioners and senior managers, and with service-users and their key workers. Focus groups sessions were also completed with mental health professionals, service-users and carers. Data collection occurred between December 2014 and June 2015. Thematic analysis was used to identify key issues. The findings identified that considerable progress had been made in the development of mental health services in the last decade, but also highlighted the significant limitations in current services. Most notably, strengths in provision included the transition from long-stay hospital care to communitybased services and person-centred approaches. The researchers identified the need to improve funding, address problems with fragmentation and gaps in service provision. Based on these findings, the authors consider the implications for practice and policy relating to the human and organisational aspects of service development. In particular, services should be developed focusing on a recovery ethos and on person-centred and relationship-based approaches. The needs of carers should additionally be considered and programmes developed to tackle stigma.
\end{abstract}

Montgomery, L, Wilson. G., Houston, S., Davidson, G., Harper, C (2018) 
What is known about this topic

- NI experiences higher levels of mental health problems than rest of the UK

- NI is a post-conflict society, with concerns about the ongoing impact of political conflict across generations.

- The Bamford Review of Mental Health and Learning Disability (2005) promoted a comprehensive range of services to support people to achieve their maximum level of functioning.

What this paper adds

- Identified strengths of 'Bamford' implementation included carefully-managed transition from long-stay hospital care to community-based services and promotion of person-centred approaches.

- Identified challenges included limited resources, continuing financial restraint and service fragmentation.

- Policy implications: Service development should prioritise recover-based, personcentred, relationship-based approaches, with consideration of carers' needs and antistigma programmes.

Montgomery, L, Wilson. G., Houston, S., Davidson, G., Harper, C (2018) 


\section{Introduction}

In recent years there has been increasing recognition of mental ill-health as a major public health issue. Mental health is now regarded as one of the four most significant causes of ill health and disability in Northern Ireland (NI) along with cardiovascular disease, respiratory disease, and cancer (Department of Health, Social Services and Public Safety (DHSSPS), 2011). The NI Study of Health and Stress, based on a nationally representative, face-to-face household survey involving 4340 individuals, reported a lifetime prevalence of $39.1 \%$ of any mental health problem, and a projected lifetime risk of 48.6\% (Bunting et al., 2012). NI has been noted to have higher levels of poor mental health than anywhere else in the United Kingdom (UK) (Leavey et al., 2009). The impact of the Troubles, the period of sustained political violence between 1969 and 1998, has been repeatedly identified as an important factor influencing the mental health of NI citizens (Social Services Inspectorate, 1998; Tomlinson, 2007).

Whilst there has been positive progress in addressing mental health needs, there has been very limited research of service-users' experiences, or mental health professionals' perspectives on the services they provide. In this context, Action Mental Health (AMH), a voluntary sector organisation established in 1963 to provide a range of services to support mental health and well-being, commissioned an evaluation of mental health services in NI. This article presents the findings from a cross-sectional survey designed to provide a snapshot of different stakeholders' perspectives on mental health services in NI (Author, 2015). The aim was to provide service-users, carers, managers and professional staff with an opportunity to 'voice' their views on the strengths of current service provision, and areas requiring further development. This article reviews some of the literature that was used to inform the evaluation, prior to offering an overview of the methods and key findings. In the conclusion, the implications for policy and service development are discussed.

\section{Policy, service and research developments in Northern Ireland}

In 2002, the DHSSPS initiated a comprehensive, independent and inclusive process of reviewing the law, policy and services relevant to mental health and learning disability in NI. The case for a higher level of investment in mental health services in NI, compared to Great Britain, was also made by the Bamford Review (2005, 2007). The resultant Bamford Vision and Action Plans promoted the development of a comprehensive range of services that would 
support people with mental health needs to achieve their maximum level of functioning, and lead as independent lives as possible (DHSSPS, 2009, 2012, 2014).

In comparison with Great Britain, NI continues to have a distinctive profile of mental health needs characterised by high levels of socio-economic deprivation and the deleterious effects of over thirty years of civil and political conflict (Bunting et al., 2013; Davidson and Leavey, 2010). For example, in every district of NI, the proportion of adults claiming benefits is higher than the average in Great Britain (MacInnes et al., 2015), and the general employment rate is 5\% lower (Joseph Rowntree Foundation, 2016). Although there have been some very positive political changes over recent years, the political focus in NI is, arguably, still on divisive, sectarian issues, rather than immediate social problems, all of which continue to impact on the population's mental health. The Troubles have also impeded social and cultural diversification. The most recent census, in 2011 , found that only $1.8 \%(32,400)$ of the usually resident population of NI belonged to minority ethnic groups (Office of National Statistics, 2016).

More generally, the policy and economic context for mental health interventions in NI is complex and multi-faceted (Prior, 1993; Queen's University Belfast Budget Analysis Project, 2013). The situation in NI is unusual in terms of the numbers of people experiencing mental health issues, the social determinants of those issues, and the structurally integrated health and social care services, with one employer, shared aims and objectives, and source of funding (Ham et al., 2013). There has also been a lack, until relatively recently, following the Good Friday Agreement in 1998, of devolved systems of government positioned to develop locally appropriate solutions. The policy context has been unstable as the NI Assembly was suspended in January 2017 and, by April 2018, has not yet been reinstated.

Concerns have been identified in relation to the continuing impact of health inequalities, austerity and the legacy of the Troubles on the population of NI (Davidson and Leavey, 2010; DHSSPS, 2011; 2012; Houdmont et al., 2012; O’Connor et al., 2014). There are challenges in identifying the exact level of investment that is required to resource mental health provision. Despite these difficulties, the McKinsey Report, on reshaping health and social care in NI, documented that the region spent less than half of England's per-capita spend on mental health problems and learning disabilities services (DHSSPS, 2010). 


\section{Development of mental health services in the UK and internationally}

Within the broader UK and international literature, a number of key themes in the development of mental health services have been identified. Having a national policy and strategic framework for mental health is deemed to be essential for raising awareness and securing the resources necessary to deliver effective services (Knapp et al., 2007). Perhaps the most significant strategic challenge for governments across Europe is how to replace institutional hospital-based care with effective community-based provision (Knapp et al., 2007), and in so doing, provide dynamic community-based needs-led services (Knapp et al., 2011).

Whilst expenditure across a range of Organisation for Economic Co-ordination and Development countries has been rising (OECD, 2014), some areas have continued to experience underinvestment in mental health services in comparison with other aspects of health expenditure (McDaid et al., 2005). Evans-Lacko et al. (2013) argued that the economic recession presented particular difficulties for people with mental health problems who could be at higher risk of losing their jobs and less likely to regain employment, with employment regarded as a key component in recovery. Although community-based services have improved in some areas in the UK, there are still substantial gaps and limitations in provision (Mental Health Foundation, 2013). There is international recognition that investing in mental health provision, including early intervention and preventative services, not only improves care and treatment for individuals and families, but also reduces the economic costs associated with mental health problems (Knapp et al., 2011; Valmaggia et al., 2009). Prioritising investment in mental health promotion has been demonstrated to provide a range of mental health, social and economic benefits (Knapp et al., 2011).

Whilst the value of effective collaboration and integration between different services has been a key aspiration of different governments in the UK for many years, inter-agency tensions seem to be endemic throughout the National Health Service (Plamping et al., 2000). As noted, NI has a major advantage in this regard through their integrated structure for the commissioning, management and provision of health and social care.

The value of working with service-users has also been recognised internationally (Wallcraft et al., 2013). Service-user involvement in mental health encompasses a wide range of activities from working in partnership at the individual level to inclusion in service planning, 
evaluation, and research (Tait and Lester, 2005). Within the UK, there has been widespread support for greater service-user involvement, at individual, strategic and leadership levels (Gilburt et al., 2014). There is, however, debate about how these forms of empowerment can be achieved, and different perspectives on the extent to which service-user involvement has become embedded in mental health policy and practice (Faulkner, 2009; Kalathil, 2013). Conklin et al. (2015), in their systematic scoping review of studies on public involvement in health care policy, concluded that there was a need for more research to determine which forms of public involvement were appropriate and effective in informing decision-making and policy development. Newbigging et al. (2015) highlighted the positive role played by mental health advocates in empowering service-users to contribute to decisions centring on their care. Moreover, across the UK, stigma and discrimination continued to be significant features of service-user and carer experiences, impacting negatively on health, wellbeing and social inclusion (Mental Health Foundation, 2013).

Finally, the importance of promoting a recovery approach in mental health, including how recovery should be defined (Shepherd et al., 2010), and how best to develop it in practice (Roberts and Hollins, 2007), has been widely debated in both the UK and the international literature. Given the multi-faceted nature of international models of recovery, Leamy et al. (2011) utilised a systematic review of the literature to develop a conceptual framework for recovery. Moving away from a medical model of care, to one that promotes a recovery ethos, involves acknowledging service-users and carers as equal partners in decisions about planning and delivering mental health services (Wilson and Daly, 2007).

\begin{abstract}
Aims
This study was commissioned by AMH to provide a critical analysis of key issues relating to the provision of mental health services in NI. Different stakeholders' perspectives on mental health services were sought to identify strengths of current service provision and areas requiring further development in relation to the realisation of the Bamford Vision, the ongoing influence of the NI context, and the degree to which NI's distinctive profile of mental health needs had been met.
\end{abstract}

\title{
Method
}

Montgomery, L, Wilson. G., Houston, S., Davidson, G., Harper, C (2018) 
Qualitative methods, including individual interviews, focus groups, and an on-line survey were utilised, gathering the perspectives of a range of stakeholders and promoting respondent triangulation. Semi-structured interviews enabled respondents to share personal experiences and opinions in a confidential environment. Focus groups were selected to empower and enable respondents with an emphasis on the joint construction of meaning. The online questionnaire was included in the design as it was recognised that some people might be reluctant, or unable, to participate in the face-to-face data collection methods.

The research was overseen by a multi-disciplinary and multi-agency steering group comprising academic staff, mental health professionals, and representatives from the nonstatutory, mental health sector. Service-users and carers were seen as key informants, and the opinions of a wide range of mental health staff, in both the statutory and voluntary sectors, were surveyed. The sample included psychiatrists, psychologists, social workers, occupational therapists and day care workers. This sample reflected the range of groups and agencies involved in commissioning, delivering and experiencing mental health services. In reflecting their core ethos, AMH commissioned this study in respect of adult mental health services; however, the findings also referred to mental health services for children when this issue had been raised by the respondents.

The interviewers adopted a standardised approach using a structured topic guide which focused on five areas: (i) the strengths of services; (ii) the limitations or gaps in services; (iii) the impact of NI's socio-political context on service development; (iv) the priorities for service development; and (v) any other pertinent issues raised by the informants. Based on the issues identified in the literature review, and on the particular interest and expertise of their respondents, the evaluators developed specific prompts for each topic.

\section{Sampling and recruitment}

The on-line survey was open to anyone to complete and was promoted through the AMH website. Purposive sampling was used for the interviews and focus groups to gain a broad and representative sample. This ensured that the participants reflected diverse organisational and professional backgrounds, including people from different social and religious categories, and where relevant, users of services experiencing a range of mental health conditions. Respondents were recruited from a range of geographical settings across NI which encompassed both rural and urban communities. Moreover, senior managers from all five, 
geographically distinct, Health and Social Care Trusts were recruited. All of the respondents were White and indigenous to NI. This may be explained by the fact that NI is, essentially, an ethnically, homogenous society in which over $99 \%$ of the population is White (Northern Ireland Statistics and Research Agency (NISRA), 2011). Importantly, there was a gender mix across the sample, and the respondents were aged between 18 and 75 years (see Table 1).

\section{Table 1: Participant details}

\begin{tabular}{|l|c|c|c|}
\hline \multicolumn{1}{|c|}{ Interviews and focus groups } & \multirow{2}{*}{ No } & \multicolumn{2}{c|}{ Gender } \\
\cline { 2 - 4 } & & Female & Male \\
\hline $\begin{array}{l}\text { Semi-structured interviews } \\
\text { Commissioners/senior managers }\end{array}$ & 7 & 1 & 6 \\
\hline $\begin{array}{l}\text { Semi-structured interviews } \\
\text { AMH service-users }\end{array}$ & 5 & 4 & 1 \\
\hline $\begin{array}{l}\text { Semi-structured interviews } \\
\text { AMH key workers }\end{array}$ & 3 & 1 & 2 \\
\hline Focus group Service-users & 8 & 4 & 4 \\
\hline Focus group Service-users & 11 & 8 & 3 \\
\hline Focus group Service-users & 3 & 0 & 3 \\
\hline Focus group Carer & 5 & 4 & 1 \\
\hline Focus Group Frontline AMH staff & 12 & 9 & 3 \\
\hline Focus Group Frontline AMH staff & 12 & 9 & 3 \\
\hline $\begin{array}{l}\text { Focus Group Frontline staff } \\
\text { Voluntary sector organisations }\end{array}$ & 4 & 4 & 0 \\
\hline $\begin{array}{l}\text { Focus groups Mental Health } \\
\text { professionals }\end{array}$ & 3 & 1 & 2 \\
\hline $\begin{array}{l}\text { Semi-structured interviews } \\
\text { Mental health professionals }\end{array}$ & 3 & 0 & 3 \\
\hline \multicolumn{1}{|c|}{ Totals } & $\mathbf{7 6}$ & $\mathbf{4 5}$ & $\mathbf{3 1}$ \\
\hline
\end{tabular}

Stakeholder organisations across NI were asked to suggest representatives to participate in the evaluation for focus groups and individual interviews. Within $\mathrm{AMH}$, the participants were given a choice to engage in interviews or focus groups. A member of the Evaluation Team contacted the stakeholder organisations and explained the purpose of the project and that potential respondents would be provided with a copy of the 'Participant Information Sheet' (PIS). The stakeholder organisation recruited respondents and confirmed their participation in 
the study after potential informants had the opportunity to read the PIS. Individuals were invited to participate by attending a focus group meeting or individual interview arranged at a convenient time and location. The evaluators were unaware of any non-respondents, or those approached who declined to take part in the study. No participants withdrew their consent during the selection process.

\section{Data gathering}

The data were gathered between December 2014 and June 2015 with different methods running concurrently. Four focus groups were conducted with staff across a range of key stakeholder organisations, namely: (i) two focus groups with frontline staff from AMH; (ii) staff from other community and voluntary sector service providers; and (iii) frontline mental health professionals working within the statutory sector, including psychiatrists, psychologists, social workers, and occupational therapists. Three staff members were unable to attend this focus group and, for logistical reasons, they were interviewed individually. Three focus groups were conducted with service-users and one with carers.

Informed consent was sought at the beginning of each focus group meeting and the participants were asked to complete and sign a 'Participant Consent Form' prior to the meeting taking place. Each focus group meeting was facilitated by a member of the Evaluation Team and lasted for approximately one hour.

Semi-structured interviews were conducted with five service-users who attended AMH. The key workers supporting these service-users were also interviewed. However, as one key worker fulfilled this role for three service-users, only three key workers were interviewed. Semi-structured interviews were also conducted with senior managers from all five HSCTs in addition to senior government commissioners from the Department of Health (DoH). Informed consent was sought at the beginning of each interview and participants were asked to complete and sign a 'Participant Consent Form' prior to the interview taking place.

The on-line questionnaire was active from December 2014 to March 2015, and promoted through the $\mathrm{AMH}$ website. It took an estimated 15 minutes to complete. In total, 276 responses were received. One third of respondents $(n=90)$ identified themselves as 'serviceusers' and 9\% $(\mathrm{n}=25)$ as a being a 'carer'; 43\% $(\mathrm{n}=119)$ were mental health professionals; 
and the remaining $15 \%(\mathrm{n}=42)$ identified as 'other' and included student nurses and health workers, former service-users, those in advocacy roles, and members of the public.

\section{Data Analysis}

The focus groups and interviews were digitally recorded and thematically analysed manually. In other words, the data were read and re-read to identify codes and themes, ensuring that such categories of meaning represented the informants' views and opinions (Braun and Clarke, 2006). A thematic analysis of the qualitative data gathered from the on-line survey was also completed. A process of co-analysis was then used to construct an overarching thematic analysis using selected quotations to illustrate common and divergent themes.

To promote reliability, the perspectives of a wide range of stakeholders were triangulated, a systematic procedure was adopted for analysing the data, and the preliminary findings were critically discussed at various points with the steering group and refelxively among the evaluators.

\section{Ethics}

The study was approved by the University's School Research Ethics Committee. Concern for the respondents' welfare was paramount, especially as the project focused on sensitive topics. The respondents were advised that they could withdraw at any time, and pause or end their participation without having to give a reason. A list of appropriate support services were made available to them, should they be needed. The participants were assured that information provided was confidential, with the exception of responses revealing risk, or serious criminal activity. They were also assured that any cited comments would not be attributed to a particular individual.

\section{Findings}

The findings are discussed under three broad categories, namely: (i) the strengths of the services; (ii) the limitations of and challenges facing the services; and (iii) the NI context impacting on the services. Within these broad topics a number of subthemes were identified; these have been presented in Table 2 and are summarised under each topic heading. Notably, there was a high level of agreement in the opinions and perceptions of the commissioners, 
service mangers, professionals, service-users and carers in relation to each of the key themes identified. Significant variations in perspectives have, however, been identified.

Table 2: Sub-themes identified in the findings

\begin{tabular}{|c|c|}
\hline Key Theme & Sub-Theme \\
\hline Strengths of the services & $\begin{array}{l}\text { Ongoing development of care in the community; } \\
\text { Professional qualities and the importance of relationship; } \\
\text { Range and quality of community-based services; } \\
\text { Service-user and carer involvement; } \\
\text { Development of a recovery approach; } \\
\text { Contribution of voluntary and community sectors; } \\
\text { Human resources }\end{array}$ \\
\hline $\begin{array}{l}\text { Limitations and } \\
\text { Challenges of Services }\end{array}$ & $\begin{array}{l}\text { Financial and resource constraints; } \\
\text { Fragmentation of service delivery and communication } \\
\text { breakdown; } \\
\text { Limitations and gaps in community-based services; } \\
\text { Limitations of hospital-based provision; } \\
\text { Supported housing services, day care, and vocational services; } \\
\text { Access to mental health services in rural areas; } \\
\text { Dominance of medical model; } \\
\text { Stigma; } \\
\text { Impact on staff morale and stress levels; } \\
\text { Concerns about leadership and the strategic challenges facing } \\
\text { mental health. }\end{array}$ \\
\hline $\begin{array}{l}\text { Northern Ireland Context } \\
\text { impacting on Services }\end{array}$ & $\begin{array}{l}\text { Impact of the Troubles on mental health; } \\
\text { Transgenerational trauma. }\end{array}$ \\
\hline
\end{tabular}

Montgomery, L, Wilson. G., Houston, S., Davidson, G., Harper, C (2018) 


\section{Strengths of the services}

The most significant development during the past decade was seen to be the move away from long-stay care in hospitals to community-based services. A change in public perceptions was noted in relation to the type of care and support now expected from mental health services, as noted by one mental health commissioner (MHC):

"People no longer live in mental health hospitals ... that practice has ended. There is an expectation that people will get the assessment, treatment, and support they require in the community" (MHC 01).

In contrast to the detrimental impact of long-term hospital care, the positive benefits for service-users came from the development of community-based services:

"The longer-term care patients have now all been moved to supported housing in the community - the tenants have really blossomed in terms of their independence, selfesteem, and self-efficacy" (MHC 02).

Many service-users (SU) also presented a positive view of community-based mental health services and contrasted this sentiment with their past experience of institutional care:

"Before, you were just doped with medication, sent away, locked away, you were too much trouble" (SU 01).

It was acknowledged that the Bamford Review had been the primary catalyst in driving the extensive change process and much progress had been identified. The range and quality of community-based provision was welcomed by the commissioners, professionals and serviceusers. The respondents identified a number of notable developments including therapeutic services, crisis response teams, forensic services, home treatment teams, rehabilitation teams, and services for people with eating and personality disorders. The crucial role that the voluntary and community sectors played in progressing service developments was also acknowledged by the commissioners. Whilst comparisons with the statutory sector were not Montgomery, L, Wilson. G., Houston, S., Davidson, G., Harper, C (2018) 
made, the service-users emphasised the role that the voluntary sector played in promoting their recovery, with day-care affording much needed structure, security and daily routine. The service-users and carers suggested that day-care provided purpose and direction, reduced boredom and unhelpful introspection, and thus assisted in the recovery process. Security came from the realisation that the day care offered was not time-limited; hence, the value of an 'open-ended service' was emphasised. Furthermore, the quality of inter-personal relationships with professional staff was identified as a core strength. Having professionals who listened and showed empathy, made a fundamental difference to the lives of serviceusers. Moreover, the knowledge, expertise and commitment of professional staff was considered to be one of the most important assets of the mental health system:

"It is really from my key worker that has stemmed all the positive things about the mental health service" (SU 02).

Person-centred approaches were specifically valued within hospital settings:

"They were very kind to me. I had a pretty bad breakdown. They were always there for me, you know ... there were some guys in there that went the extra mile for you" (SU 03).

Several carers (C) highlighted the importance of home visits from professionals, enabling observations in 'lived situations', appreciating the constraints and challenges facing the carers, and the contextual factors impinging on the situation:

"... an understanding that the carer knows the person. That's the person who is spending time with their loved one ... to me, that is the difference between things breaking down and stuff being prevented" (C 01).

The development of service-user and carer involvement at all levels, including the planning and commissioning of services, was viewed as a positive development by the commissioners:

"We are moving much more towards the "no decision about me without me" (MHC $03)$.

Many service-users indicated that they 'had a voice' within the wider system, attributing this, in large part, to the support of professional key worker staff. Mental health professionals 
(MHP) also highlighted that the active involvement of service-users as peer advocates had been a major development in service provision:

"One of the big successes is the use of patient advocates ... that's been fantastic ... works really well” (MHP 01).

Finally, whilst services were moving more towards a 'recovery' ethos, there were different perspectives on what constituted a recovery approach. The commissioners conceded that further developmental work was required to ensure this orientation was firmly embedded in working practices:

"There is a tension between what might be the service-user view of what a recovery focused service would be and a lot of professionals' views ... you don't change culture overnight” (MHC 04).

\section{Limitations of and Challenges facing Services}

The greatest challenge facing mental health services was seen to stem from limited resources and the impact of continuing financial restraint. It was contended that there was a lack of parity with general hospitals and physical health care when it came to resource allocation. From this contention, many of the other gaps and limitations emerged.

Respondents from all groups expressed concerns about the fragmentation of mental health services and the detrimental impact of poor communication between the different parts of the system. The interface between the hospital and community, and the transition from children's to adult mental health services, was a central concern in this regard, with the system being viewed as compartmentalised:

"Different specialist teams ... have created unnatural barriers for service-users in navigating across the system." (MHC 05).

It was felt that restrictive eligibility criteria, coupled with poor communication with serviceusers and carers, had led in some areas to breakdowns in continuity and a lack of seamlessness in service delivery.

Mental health professionals and commissioners accepted that the transition from children's to adult services was particularly problematic. Notwithstanding the development in community- 
based services, an identified over-reliance on hospitalisation was attributed to inadequacies in community care, which tended to be most acute in rural areas.

Moreover, tensions were identified in providing sufficient services to meet the sometimes conflicting needs of both service-users and carers:

"One of the biggest challenges is family perceptions - individuals with severe and enduring mental illness don't want to be in hospital, families often want them in hospital - that is a tension for us" (MHC 06).

A medical model approach was still seen to dominate care in certain areas:

"Still overly based on medical interventions and biomedical model. Intervention tends to be reactionary as opposed to preventative" (MHP 02).

One main variation in the participants' perspectives was noted. Thus, whilst some carers and staff heralded greater participation as an important advance, a number of carers reported that such gains were thwarted by problems between interfaces, and poor communication between different professionals, specialisms and facilities:

"There is no communication. The carer is completely left out. You are in the lurch ... You know, you get these sort of template letters and that's it" (C 02).

In contrast to the professionals' views, service-users and carers indicated that aspects of the system failed to treat them as 'people' reducing them to 'problems' to be managed. They also identified concerns around stigma:

"You have this feeling that you keep your head down and you don't talk to people because your family members are mentally ill" (C 03).

Critically, many of the carers expressed a sense of isolation, feeling overwhelmed and burdened throughout their lives.

The lack of funding and resources also impacted negatively on the morale of professional staff and managers. Commissioners and professionals depicted overloaded, and often stressed professionals in the statutory sector struggling to cope with large caseloads and increasing demand. A risk averse approach tended to restrict professional practice and limit service-user choice. As such, there was dissatisfaction with existing outcome measures in mental health Montgomery, L, Wilson. G., Houston, S., Davidson, G., Harper, C (2018) 
and a requirement to adequately capture the quality of service delivery in a more meaningful way. Finally, the respondents also expressed concern about both the scale of the strategic challenges now facing the further development of mental health services, and what they perceived as a gap in leadership:

"There is a lack of leadership from politicians and funders, and therefore there appears to be no definitive healthcare provision for people experiencing mental ill health. There are too many short-term programmes for an illness that requires lifetime management" (MHP 03).

\section{The Northern Ireland Context impacting on Services}

A small number of respondents identified some positive features of the NI context which were helpful for promoting good mental health, and which they felt were not experienced by other regions in the UK or further afield:

“Communities work reasonably well ... people have resettled well and our readmission rates are generally good ... a sense of community and belonging” (MHP 04).

However, the majority of respondents who commented expressed negative views about the impact of the Troubles on the population's mental health. One carer suggested:

"Because to me the Troubles, they are at the heart of an awful lot of it ... the Troubles mean that there is so much mental illness here, so much stress and so much depression in so many areas"'(C 04).

Mental health professionals and commissioners agreed that professional services were struggling to address Troubles-related mental health needs:

"(We need to) acknowledge that we are in a post-conflict situation and address the mental health issues that that brings with it ... We are in no way addressing this issue on the scale it requires" (MHP 05).

This Troubles-related legacy was considered to be trans-generational and long-term in its impact:

“There's a whole generation that has been damaged" (SU 04). 
Lastly, the current recession compounded a legacy of high levels of social deprivation, poverty, and unemployment. More specifically, in expressing concerns about future funding, stakeholders suggested that one of the most significant strategic challenges facing mental health was lack of parity with physical (acute hospital) health care. Indeed, the comparison between mental and physical ill health was a recurring theme in the feedback obtained:

"But how can they treat mental health on an equal basis with other disabilities when you get the cancer unit in the $\mathrm{X}$ hospital sitting on the front of the road, and the mental health place somewhere in the darkness" (C 05).

\section{Discussion}

An overview of the current state of mental health service provision in NI was presented from the perspectives of the commissioners, senior managers, mental health professionals, serviceusers and carers. The literature review of policy, service and research developments in NI and beyond identified the following main themes: the impact of the Bamford Review; the role of service-user involvement; the integration of health and social care in NI; the funding of mental health services; and the implementation of the recovery approach. These are now considered in light of the findings of this evaluation. An additional key issue which arose from the findings, about the need for leadership and clear, coordinated policy, will also be discussed.

Mental health services in NI are seen to have many strengths, and much has been achieved in realising the Bamford Vision for improving mental health provision. Significant progress has been made in moving away from long-stay hospital care towards services that are based primarily in the community although this is an unending process. The dedication and commitment of professional staff in both the statutory and voluntary sectors was also identified as a central and positive feature of service provision.

Whilst there is widespread support for service-user involvement at all levels of mental health service provision (Gilburt et al., 2014), there is debate about the extent of such involvement and evidence for its impact remains uncertain (Conklin et al., 2015; Faulkner, 2009; Kalathil, 2013). Whilst service-user involvement, a key recommendation articulated by the Bamford Review, was broadly endorsed in this study, the extent to which it was achieved was variable. Although all groups expressed a view that service-users and carers 'had a voice' in the 
system, some service-users and carers felt that aspects of the system failed to treat them as 'people', leaving them feeling 'completely left out' and isolated.

The integrated model of statutory health and social care, which has been in place in NI since 1972, has been found to have some benefits for multidisciplinary working (Reilly et al., 2004). In this study, the voluntary and community sectors, working in conjunction with statutory services, were identified as making a significant contribution to meeting mental health needs and to progressing innovative service developments. Arguably, this provided an additional level of integration to the existing structurally integrated services in NI. However, a lack of organisational barriers alone is not necessarily sufficient for effective integration (Chong et al., 2012). Whilst the NI structural systems are considered conducive towards interagency working, concerns around the fragmentation of services and associated difficulties of communication and transfer between services remain prominent.

Respondents from all of the groups surveyed expressed serious concerns about the detrimental impact of continuing efficiency savings in mental health and their negative impact on service development. Progress, already achieved, could be lost and much needed developments, such as improvements to therapeutic services, respite care and early intervention services, might not be realised. The funding and resource inequalities between mental health and physical health needs have been highlighted throughout the UK. Whilst mental illness accounts for $23 \%$ of the total burden of disease, it receives only $13 \%$ of NHS health expenditure in spite of the existence of cost-effective treatments (Layard et al., 2012).

Whilst significant progress had been made on promoting a recovery ethos in NI, in keeping with the findings of other studies (Stuart et al., 2016), different perspectives on what constituted a recovery approach were identified. Park et al. (2014) acknowledged that a recovery ethos represented a fundamental shift in practice which was in conflict with traditional bio-medical models and goals. Sustained action is needed on many fronts to shift culture and practice in mental health systems. Similarly, in this study, whilst a recovery ethos was identified, a medical model approach was also still seen to dominate care in certain areas, with intervention described as reactive as opposed to preventive.

Finally, together with highlighting the need for additional funding, the respondents identified that a vacuum in leadership had developed post-Bamford, and there had been a loss of focus, drive, and ambition for service improvement. Given the current climate of financial restraint, 
and the scale of strategic challenges facing mental health, strong leadership was deemed to be crucial in sustaining the progress and achieving further service improvement.

Promoting good mental health and well-being in NI is vital for individuals and families if this society is to grow and prosper. Developing mental health services presents complex challenges. Whilst this evaluation does not claim to provide a blueprint with all the answers, it identifies opportunities for service development and signposts directions for further improvement in the planning and delivery of future services.

\section{Limitations of the Study}

Whilst the study provided an overview of the current state of mental health service provision from a range of perspectives, participant numbers were small and they were not necessarily representative of the full range of views. The inclusion of mental health services to children and adolescents would have provided a more comprehensive evaluation. Moreover, many of the findings were broad in scope and would benefit from more detailed and specific exploration.

\section{Conclusion}

This evaluation aimed to present a picture of how people with mental health problems in NI are supported in order to help inform the planning and funding of future services. The findings have implications for policy and practice in relation to both the human and the organisational aspects of service delivery. Service-users identified 'listening' and 'relationship' as vital to service provision, expressing concern about how they were perceived by the system, and about the lack of recognition of the carers' contribution. Developing services founded on the recovery ethos, and based on person-centred and relationship-based approaches, was seen to be central. Critically, the specific needs of carers should be considered, and consideration given to the development programmes targeting stigma (Corrigan et al., 2016).

Turning to organisational priorities, the need for sufficient funding is a clear theme throughout the literature and is reinforced by the findings of this evaluation. How the identified fragmentation and local variations in service provision can be addressed should also be considered. An identified mental health champion may provide the leadership, focus and accountability necessary to achieve significant change, particularly in the context of 
wider political uncertainties. The specific needs of those affected by the Troubles should also be addressed. Finally, the evaluation reinforced the importance of all those involved in mental health services, across sectors, working together to achieve positive change.

Montgomery, L, Wilson. G., Houston, S., Davidson, G., Harper, C (2018) 


\section{References}

Author (2015). Regress? React? Resolve?: An evaluation of mental health service provision in Northern Ireland. Belfast: Action Mental Health. Available at:

https://www.researchgate.net/publication/306003535_Regress_React_Resolve_An_evaluatio

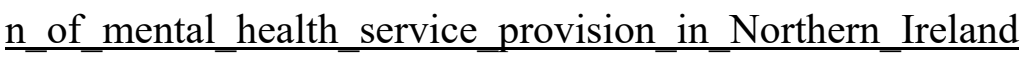

Bamford Review of Mental Health and Learning Disability. (2005) A Strategic Framework for Adult Mental Health Services. Belfast: DHSSPS. Available at:

http://www.dhsspsni.gov.uk/index/bamford/published-reports.htm

Bamford Review of Mental Health and Learning Disability. (2007) A Comprehensive Legal Framework for Mental Health and Learning Disability. Belfast: DHSSPS. Available at: http://www.dhsspsni.gov.uk/index/bamford/published-reports.htm

Braun, V., \& Clarke V. (2006) Using thematic analysis in psychology. Qualitative Research in Psychology 3, 77-101.

Bunting, B.P., Murphy, S.D., O'Neill, S.M. \& Ferry, F.R., (2012) Lifetime prevalence of mental health disorders and delay in treatment following initial onset: Evidence from the Northern Ireland Study of Health and Stress. Psychological Medicine 42, 1727-1739. DOI: https://doi.org/10.1017/S0033291711002510

Bunting, B.P., Ferry, F.R., Murphy, S.D., O'Neill, S.M. \& Bolton D. (2013) Trauma associated with civil conflict and posttraumatic stress disorder: Evidence from the Northern Ireland study of health and stress. Journal of Traumatic Stress 26, 134-141.

Chong, R., Tan, W-M., Wong, L-M., \& Cheah, J., (2012) Integrating mental health: the last frontier. International Journal of Integrated Care, 12, 1-3. 
Conklin, A., Morris, Z. \& Nolte, E. (2015) What is the evidence base for public involvement in health-care policy?: results of a systematic scoping review. Health Expectations, 18, 153165. DOI: $10.1111 /$ hex.12038

Corrigan, P. W., Schmidt, A., Bink, A. B., Nieweglowski, K., Al-Khouja, M. A., Qin, S., \& Discont, S. (2016) Changing public stigma with continuum beliefs. Journal of Mental Health, 1-8. doi.org/10.1080/09638237.2016.1207224

Davidson, G. \& Leavey, G., (2010) Promoting mental health in Northern Ireland: Addressing division, inequality and stigma. Journal of Public Mental Health 9, 6-15. doi.org/10.5042/jpmh.2010.0698

Department of Health, Social Services and Public Safety (2009) Delivering the Bamford Vision: The Response of the Northern Ireland Executive to the Bamford Review of Mental Health and Learning Disability. Action Plan 2009-2011, Belfast: Department of Health, Social Services and Public Safety. Available at:

http://www.dhsspsni.gov.uk/bamford_action_plan_2009-2011.pdf

Department of Health, Social Services, and Public Safety. (2010) Reshaping the System: Implications for Northern Ireland's Health and Social Care Services of the 2010 Spending Review ('McKinsey Report'). Belfast: Department of Health, Social Services, and Public Safety. Available at: http://www.dhsspsni.gov.uk/index/mckinseyreport.htm

Department of Health, Social Services, and Public Safety. (2011) Transforming Your Care: A Review of Health and Social Care in Northern Ireland. Belfast: Department of Health, Social Services, and Public Safety. Available at: http://www.transformingyourcare.hscni.net/wpcontent/uploads/2012/10/Transforming-Your-Care-Review-of-HSC-in-NI.pdf 
Department of Health, Social Services, and Public Safety. (2012) Evaluation of the Bamford Review Action Plan 2009-2011. Belfast: Department of Health, Social Services, and Public Safety. Available at: http://www.dhsspsni.gov.uk/bamford-evaluation-action-plan20092011.pdf.

Department of Health, Social Services, and Public Safety (2014a) Bamford Action Plan 201215: Monitoring Report-November 2014, Belfast: Department of Health, Social Services, and Public Safety. Available at: http://www.dhsspsni.gov.uk/bamford-monitoring-reportnovember-2014.pdf

Evans-Lacko, S., Knapp, M., Thornicroft, G. \& Mojtabai, R., (2013) The mental health consequences of the recession: Economic hardship and employment of people with mental health problems in 27 European countries. PLoS One, 8(7): e69792. DOI: 10.1371/journal.pone.0069792.

Faulkner, A., (2009) Service User and Carer Involvement in the National Mental Health Development Unit: Scoping Report, London: National Survivor User Network.

Gilburt, H., Edwards, N. \& Murray, R. (2014) Transforming Mental Health: A Plan of Action for London, London: The King's Fund.

Ham, C., Heenan, D., Longley, M., \& Steel, D.R. (2013) Integrated care in Northern Ireland, Scotland and Wales: Lessons for England, London: The King's Fund.

Houdmont, J., Kerr, R. \& Addley, K. (2012) Psychosocial factors and economic recession: The Stormont study. Occupational Medicine, 62, 98-104. doi.org/10.1093/occmed/kqr216 
Joseph Rowntree Foundation. (2016) Monitoring Poverty and Social Exclusion in Northern Ireland. Available at: https://www.jrf.org.uk/report/monitoring-poverty-and-social-exclusionnorthern-ireland-2016

Kalathil, J. (2013) Dancing to our own tunes: Reassessing black and minority ethnic mental health service user involvement. London: CC Media Group.

Knapp, M., McDaid, D., Thornicroft, G. \& Mossialos, E. (2007) Mental Health Policy and Practice across Europe: An overview in Knapp, M.,McDaid, D., Mossialos, E. \& Thornicroft, G. (editors.), Mental Health Policy and Practice across Europe, New York: Open University Press, pp. 1-14.

Knapp, M., McDaid, D. \& Parsonage, M. (editors) (2011). Mental Health Promotion and Mental Illness Prevention: The Economic Case, London: Department of Health.

Layard, R., Banerjee, S., Bell, S., Clark, D., Fielding, S., Knapp, M., Meacher, M., Naylor, C., Parsonage, M., Scott, S.V. \& Strang, J. (2012) How mental illness loses out in the NHS. a report by The Centre for Economic Performance's Mental Health Policy Group. Available at:

http://eprints.lse.ac.uk/44572/1/How\%20mental\%20illness $\% 20$ loses $\% 20$ out $\% 20 \mathrm{in} \% 20$ the $\% 2$ 0NHS\%28LSERO\%29.pdf

Leamy, M., Bird, V., Le Boutillier, C., Williams, J., Slade, D. (2011). Conceptual framework for personal recovery in mental health: systematic review and narrative synthesis. British Journal of Psychiatry, 199: 445-452. DOI: 10.1192/bjp.bp.110.083733

Montgomery, L, Wilson. G., Houston, S., Davidson, G., Harper, C (2018) 
Leavey, G., Galway, K., Rondon, J., \& Logan, G. (2009) A Flourishing Society: Aspirations for emotional health and wellbeing in Northern Ireland. Northern Ireland Association for Mental Health.

MacInnes, T., Tinson, A., Hughes, C., Barry Born, T. \& Aldridge, A. (2015) Monitoring Poverty and Social Exclusion. York: Joseph Rowntree Foundation.

McDaid, D., Curran, C. \& Knapp, M., (2005) Promoting mental well-being in the workplace: A European policy perspective. International Review of Psychiatry, 17, 365-373. doi.org/10.1080/09540260500238397

Mental Health Foundation, (2013) Starting Today: The Future of Mental Health Services, London: King's College London.

Newbigging, K., Ridley, J., McKeown, M., Machin, K., \& Poursanidou, K. (2015) When you haven't got much of a voice': an evaluation of the quality of Independent Mental Health Advocate (IMHA) services in England. Health and Social Care in the Community, 23, 313324. DOI: $10.1111 / \mathrm{hsc} .12153$

NISRA (2011). Census, 2011, Available at http://www.nisra.gov.uk/Census/2011_results_population.html.

Northern Ireland Association for Mental Health. (2004) Counting the Cost: The Economic and Social Cost of Mental Illness in Northern Ireland, Belfast: Sainsbury Centre for Mental Health.

Northern Ireland Executive. (2012) Programme for Government 2011-2015, Belfast: Northern Ireland Executive. Available at: http://www.northernireland.gov.uk/pfg 
O’Connor, R.C., Rasmussen, S. \& Hawton, K. (2014) Adolescent self-harm: A school-based study in Northern Ireland. Journal of Affective Disorders, 159, 46-52.

https://doi.org/10.1016/j.jad.2014.02.015

Office of National Statistics. (2016) Northern Ireland population mid-year estimate.

Available at:

http://www.ons.gov.uk/peoplepopulationandcommunity/populationandmigration/populatione stimates/timeseries/nipop/pop

Organisation for Economic Cooperation and Development. (2014) Focus on Health: Making Mental Health Count, Paris: OECD.

Park, M.M., Zafran, H., Stewart, J., Salsberg, J., Ells, C., Rouleau, S., Estein, O. \& Valente, T.W.(2014) Transforming mental health services: a participatory mixed methods study to promote and evaluate the implementation of recovery-oriented services. Implementation science 9,119, doi:10.1186/s13012-014-0119-7

Plamping, D., Gordon, P. \& Pratt, J. (2000) Practical partnerships for health and local authorities. British Medical Journal, 320 (7251), 1723-1735.

Prior, P. (1993) Mental Health and Politics in Northern Ireland: A History of Service Development, Aldershot: Avebury.

Queen's University Belfast, Budget Analysis Project. (2013) Human Rights Obligations and Budgeting for Mental Health in Northern Ireland, Belfast: Queen's University Belfast. Available at: http://www.qub.ac.uk/schools/SchoolofLaw/Research/HumanRightsCentre/ResearchProjects/ BudgetAnalysis/Documents/ 
Reilly, S., Challis, D., Burns, A. \& Hughes, J. (2004) The use of assessment scales in old age psychiatry services in England and Northern Ireland. Aging \& Mental Health, 8, 249-255. doi.org/10.1080/13607860410001669787

Roberts, G. \& Hollins, S. (2007) Recovery: our common purpose? Advances in Psychiatric Treatment, 13, 397-399. DOI: 10.1192/apt.bp.107.004101

Shepherd, G., Boardman, J. \& Burns, M. (2010) Implementing Recovery. A methodology for organisational change. London: Sainsbury Centre for Mental Health.

Social Services Inspectorate. (1998) Living with the Trauma of the Troubles. Belfast: Social Services Inspectorate.

Stuart, S. R., Tansey, L., \& Quayle, E. (2016) What we talk about when we talk about recovery: a systematic review and best-fit framework synthesis of qualitative literature. Journal of Mental Health, 1-14. doi.org/10.1080/09638237.2016.1222056

Tait, L. \& Lester, H. (2005) Encouraging user involvement in mental health services. Advances in Psychiatric Treatment 11, 168-175. doi: 10.1192/apt.11.3.168

Tomlinson, M., (2007). Suicide and young people: the case of Northern Ireland. Child Care in Practice 13, 435-443. doi.org/10.1080/13575270701504802

Valmaggia, L.R., McCrone, P. \& Knapp, M. (2009) 'Economic impact of early intervention in people at high risk of psychosis', Psychological Medicine, 39, 1617-1626. doi.org/10.1017/S0033291709005613

Wallcraft, J.A., Amering, M, Freidin, J, Davar., B, Froggatt., D, Jafri. H., Javed, A., Katontoka, S., Raja, S., Rataemane, S., \& Steffen S. (2013). Partnerships for better mental health worldwide: WPA recommendations on best practices in working with service-users and family carers. World Psychiatry, 10, 229-236. DOI: https://doi.org/10.1002/j.2051$\underline{5545.2011 . t b 00062 . x}$ 
Wilson, G. \& Daly, M. (2007) Shaping the future of mental health policy and legislation in Northern Ireland: The impact of service-user and professional social work discourses British Journal of Social Work, 37, 423-439. DOI:

https://doi.org/10.1093/bjsw/bcm021

Montgomery, L, Wilson. G., Houston, S., Davidson, G., Harper, C (2018) 